\title{
Melodrama en el Altiplano. Maltrato infantil, minería ilegal y salud mental en tres melodramas puneños
}

\author{
Emilio Bustamante Quiroz \\ (Universidad de Lima)
}

Recibido: 12/11/2016

Aprobado: 6/12/2016

\begin{abstract}
Resumen. Se destaca que, en la producción cinematográfica regional, el género al que más se ha recurrido es el melodrama; y que la región que mayor número de melodramas ha dado es Puno. Se reseñan las características del género, y se analizan tres películas melodramáticas realizadas por cineastas juliaqueños: El hijo del viento de Flaviano Quispe, Amor en las alturas de Percy Pacco, y Marcados por el destino de Óscar Gonzales Apaza. Se describe cómo han sido empleadas las convenciones del género en estos filmes (lo que ha permitido una eficaz comunicación con el público), y cómo se abordan en ellos problemas actuales de la región.
\end{abstract}

Palabras clave: cine / cine peruano / cine regional / melodrama / Puno / Juliaca

\section{Melodrama in the Apltiplano. Child Abuse, Illegal Mining and Mental Health in Three Puno Melodramas}

\begin{abstract}
Aвstract. It is noticeable that, in regional Peruvian cinematography, the most common genre is melodrama, and that the region that has produced the most melodramas is Puno. The characteristics of this genre are reviewed and three melodramas by Juliaca filmmakers are analyzed: Flaviano Quispe's El hijo del viento, Percy Pacco's Amor en las alturas, and Marcados por el destino by Óscar Gonzales Apaza. The way genre conventions have been employed in these films (which has enabled effective communication with the public) is described, as well as the way the current issues in the region are addressed therein.
\end{abstract}

Keywords: cinema / peruvian cinema / regional cinema / melodrama / Puno / Juliaca 


\section{Introducción}

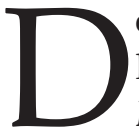
esde 1996 (año en que se realizó la película ayacuchana Lágrimas de fuego) se ha desarrollado en el Perú un cine de bajo presupuesto producido fuera de la capital de la República. Hasta el año 2015 hemos llegado a contar 147 largometrajes fruto de esta actividad, entendiendo como largometrajes - de acuerdo a la ley peruana- a las películas de más de 75 minutos. La mayoría de estos filmes se han exhibido comercialmente en salas municipales, locales comunales, escuelas o al aire libre. Sin embargo, son ignorados en Lima y prácticamente desconocidos en el extranjero; muy pocos han tenido acceso al circuito de exhibición de los multiplex y a festivales internacionales.

Las regiones de mayor actividad cinematográfica son Ayacucho (38 largos), Puno (36), Junín (21) y Cajamarca (19). En estas regiones el cine que se produce está constituido predominantemente por películas de ficción, que emplean una narrativa de género y se hallan orientadas a un público popular. Los géneros a los que más se ha recurrido son el melodrama (38 películas) y el horror (33). La región donde se ha producido mayor cantidad de melodramas es Puno con 16 películas de este género; la mayoría de los melodramas puneños han sido dirigidos por cineastas de Juliaca (12). Consideramos que el tratamiento privilegiado del género en Puno tiene relación con condiciones y fenómenos sociales propios de la región, y de la ciudad de Juliaca en particular ${ }^{1}$.

El melodrama surge históricamente como un espectáculo caracterizado por el exceso estilístico y dirigido prioritariamente a un público urbano de origen campesino que busca una orientación moral en un mundo en transformación (Martín Barbero, 1991; Brooks, 1995). No es casual que el melodrama sea el género preferido por los cineastas de Juliaca, una de las ciudades peruanas con importante migración rural y con más alta tasa de crecimiento en las últimas décadas en el Perú (Bordas, 2009, p. 232); crecimiento que ha originado profundos cambios no solo económicos sino también sociales, psicológicos y éticos en la población. Los relatos melodramáticos, históricamente, han aludido a problemas reales, pero sus resoluciones consoladoras han apuntado a reforzar valores tradicionales; aunque muy cuestionados en cuanto alentarían una actitud pasiva de las masas frente a acontecimientos socioeconómicos (presentados como reveses del destino), han sido también valorados en cuanto discursos en los que se

1 Los datos aquí señalados han sido obtenidos durante una investigación sobre el cine regional peruano que el autor ha realizado para el Instituto de Investigación Científica de la Universidad de Lima. 
hallan matrices populares y representaciones de auténticos conflictos sociales y vivencias populares (Martín Barbero, 1987; Herlinghaus, 2002).

En el presente artículo analizaremos tres largometrajes juliaqueños que se rigen por las convenciones del melodrama y se refieren a tres problemas críticos de la región Puno: el desamparo infantil, los estragos producidos por la minería ilegal, y el deterioro de la salud mental. Los filmes son: El hijo del viento (2008) de Flaviano Quispe Chaiña, Amor en las alturas (2008) de Percy Pacco Lima, y Marcados por el destino (2009) de Óscar Gonzales Apaza. Estos largometrajes han tenido gran acogida de público en su región, debido -en parte-al empleo de las convenciones de género y a los temas que abordan, tan cercanos a la población a la que se dirigen. Se trata también de filmes con un considerable nivel estilístico que, sin embargo, han sido ignorados por la crítica capitalina.

Nuestra intención es contribuir a valorar estas películas que recurren a las convenciones del melodrama para representar a poblaciones vulnerables, señalar problemas cuya solución sigue siendo postergada por el Estado, y expresar vivencias populares ante cambios sociales que alteran una forma tradicional de vida. Queremos destacar la importancia de estos filmes a menudo menospreciados por el establishment cinematográfico limeño y los canales de distribución-exhibición vinculados a las grandes empresas cinematográficas y los festivales internacionales.

\section{El melodrama}

Definiremos al género, siguiendo a Estébanez Calderón, como un modelo estructural que sirve como criterio de clasificación y agrupación de textos atendiendo a semejanzas de construcción, temática y modalidad de discurso, y como marco de referencia para autores y público (Estébanez Calderón, 2001, p. 466). Aunque el autor citado se refiere a los géneros literarios, su definición es aplicable también a los géneros audiovisuales, $\mathrm{y}$, de acuerdo a esta, precisaremos ciertas constantes temáticas, de construcción narrativa y de empleo de lenguaje (en este caso audiovisual) en el género melodramático.

El melodrama aparece en Europa a fines del siglo xviII como espectáculo popular (Martín Barbero, 1987, p. 124; Thomasseau, 1984, p. 11), luego se extiende a la literatura folletinesca del siglo $\mathrm{xIX}$, para llegar en el siglo $\mathrm{xx}$ al cine, la radio y la televisión. Es por ello que algunos autores prefieren hablar de una imaginación melodramática que recorre varios medios y épocas (Brooks, 1996; Herlinghaus, 2002). Los creadores de melodramas suelen ser artistas surgidos del seno de las clases hegemónicas que emplean en sus obras tanto fuentes clásicas (en especial la tragedia griega) como populares (manifestadas sobre todo en una estética del exceso). 
Martín Barbero ubica el origen del melodrama escénico en la época de las migraciones campesinas a las ciudades obreras luego de la revolución industrial, y señala que brinda una orientación moral a sus consumidores (esas masas migrantes) en un mundo en transformación. El eje temático fundamental del género melodramático es aquel que opone el vicio a la virtud. En un mundo que se percibe como caótico, donde se han roto los viejos lazos comunales, es fácil perderse física y moralmente; el melodrama propone la práctica de la virtud como guía para transitar y sobrevivir, y alerta sobre la tentación del vicio como pasaporte seguro a la verdadera desgracia. Aunque el melodrama no oculta las desigualdades sociales ni la injusticia de una sociedad dividida en clases, da pautas para comportarse "correctamente" de acuerdo a valores burgueses, evitar la rebelión y confiar en el destino que premiará la conducta virtuosa (Martín Barbero, 1987, pp. 124-132; Thomasseau, 1984, p. 12).

Además del eje primordial virtudvicio (en torno al cual se ordenarán maniqueamente víctimas y villanos), se hallan en el melodrama los temas de filiación (bastardía, incestos, abandonos, padres desconocidos, hijos pródigos) y amores contrariados (por diferencias de clase social, raza, edad o enconos familiares).

La estructura narrativa del melodrama es circular. Se inicia con la pérdida de un paraíso, por parte del protagonista, a causa de una falta propia o ajena que deja una herida abierta (la hamartia griega), continua con un sufrimiento que se percibe injusto y que se agudiza cada vez más con la añoranza del pasado (melancolía), hasta que llega un reconocimiento (la anagnórisis griega) que conduce al desenlace, el cual, si no es feliz, es al menos consolador y sugiere una afirmación de los valores establecidos (Pérez Rubio, 2004, pp. 23-143).

Si bien el final feliz o consolador del melodrama ha sido denunciado como mistificador y alienante, también se ha destacado que muchos relatos melodramáticos atrajeron a sus consumidores más por la injusticia y las desigualdades que describían que por sus inverosímiles desenlaces.

A diferencia de la novela burguesa y de los filmes que siguen el modo narrativo clásico (Bordwell, 1996, pp. 156-204), la causalidad entre los acontecimientos no es rígida y, en cambio, hay cierta licencia para la ocurrencia de casualidades que en otro tipo de narraciones resultarían poco creíbles.

Los roles que cumplen los personajes en el melodrama se hallan también muy convencionalizados (Martín Barbero, 1987, pp. 129-130). El papel de víctima lo asume a menudo el protagonista, y el antagonista tiene el rol de traidor (llamado también villano), a ellos se suman el justiciero (a través de quien obra finalmente el destino), y el bobo o bufón (que aligera el conflicto).

El estilo del melodrama se basa en el exceso (Martín Barbero, 1987; Pérez 
Rubio, 2004; Brooks, 1995, pp. 24-80). De lo que se trata es de evidenciar las emociones intensas, pues el melodrama, como la tragedia griega, busca provocar en el espectador lástima por el o la protagonista y temor por la suerte que le espera. El exceso puede ser de diferente tipo. En el melodrama audiovisual puede manifestarse en las actuaciones o en la música, a menudo más enfáticas que en el mero drama de origen burgués (signado, al contrario, por la contención), en los planos (preferencia por los primeros planos que potencien la expresión de los sentimientos), en los movimientos de cámara (vistosos, e incluso aparatosos), en la fotografía (con colores saturados que evidencien la intensidad de las emociones, o claroscuros que simbolicen el conflicto entre el vicio y la virtud), y en determinados escenarios o decorados (la ciudad maldita frente al campo bucólico; orfanatos, cárceles, hospitales y cementerios que representen los grandes temores al desamparo, la prisión, la enfermedad y la muerte; estaciones de tren, buses o aeropuertos que enmarquen despedidas dolorosas, arribos esperanzados, y reencuentros lacrimosos; mansiones con escaleras que aludan al ascenso y al descenso social; ventanas que motiven la mirada melancólica hacia un exterior que simbolice el pasado; espejos que den cuenta del transcurrir del tiempo en los rostros pero que también sean instrumentos de reconocimiento, al igual que fotografías, cartas y relicarios).

\section{Tres melodramas de la región Puno}

\subsection{El hijo del viento}

El tema de la niñez desamparada ha sido motivo de preocupación en Puno desde décadas atrás. En 1962, Francois Bourricaud observaba la "dislocación del lazo familiar" como consecuencia del relajamiento del control de la comunidad, y relataba su visita "a algunas familias miserables cuyos hijos habían pasado a cargo del Centro Materno Infantil" (2012, p. 162). Aunque los índices de niños con documentos de identidad y de conclusión de estudios primarios han aumentado considerablemente, se sigue estimando que el 69 \% de los niños en Puno vive en una situación de pobreza y el 51\% reside en zonas rurales. Además, como se sabe, los niños de esta región son los más afectados por el friaje, y se hallan en riesgo de enfermedades respiratorias y oftalmológicas (INEI y Unicef, 2011, pp. 168-169).

Los filmes sobre niños en orfandad y peligro son varios en Puno: Juanito, el huerfanito (2004, director: Flaviano Quispe Chaiña), El hijo del viento o Buscando a papá (2008, director: Flaviano Quispe Chaiña), Niños pobres (2009, director: Julián Miranda), Camino a la verdad o Hermanito perdido (2010, director: Elmer Estofanero), y Matar para vivir, la cruel decisión (2013, director: Edgard Ticona Mamani). Estas películas han gozado del favor del 
público local, como recordaba el director andahuaylino Víctor Zarabia, quien al explicar el motivo de que su filme de acción y artes marciales $E l$ último guerrero chanka no tuviera gran acogida en Juliaca, señalaba: "Allá les gusta las películas de huerfanitos" (entrevista personal).

Cuando Flaviano Quispe Chaiña estrenó El hijo del viento en el 2008 era ya uno de los cineastas más conocidos de la región Puno. En el 2001 debutó como director con el largo Maylli, el abigeo (2001), un áspero drama social de bajo costo y potentes imágenes sobre un ladrón de ganado expulsado de su comunidad en el Altiplano. En el 2004 estrenó Juanito, el huerfanito, melodrama sobre un niño campesino huérfano de madre que no regresaba al hogar paterno luego de ser timado por un estafador cuando iba por víveres al mercado de la ciudad. El éxito de Juanito, el huerfanito fue inmediato: después de ser exhibido varios fines de semana en el teatro municipal de Juliaca, hizo un recorrido por distintas ciudades del país y llegó a ser una de las pocas películas regionales estrenadas comercialmente en Lima. Según Quispe Chaiña, Juanito el huerfanito sumó 636 mil espectadores en sus exhibiciones públicas. Además, se trata de una de las películas peruanas más pirateadas. En el 2006, Quispe Chaiña ganó el primer concurso de proyectos de largometraje exclusivo para regiones convocado por el Consejo Nacional de Cinematografía con Sobrevivir en los Andes; sin embargo, antes de realizar ese proyecto, produjo y estrenó El hijo del viento.

En El hijo del viento, Alicia, una joven campesina, es violada por Gustavo, un policía citadino que la deja embarazada y la abandona. Doce años después, José, el hijo de ambos, descubre que su padre no ha muerto, como se lo contó su madre, acusa a Alicia de mentirosa, y emprende la búsqueda de su progenitor; pero solo encuentra el rechazo de este, y la muerte en un accidente de carretera. Cuando está agonizando, José le pide perdón a Alicia, quien a su vez le ruega también perdón a su hijo por no haberle contado oportunamente la verdad sobre su padre. Una imagen final muestra a José yendo en bicicleta por un sendero hacia el sol.

El largo tiene un acabado profesional del que carecían las películas anteriores de Quispe Chaiña. Desde el guion se trata de evitar la falta de causalidad común a muchas películas regionales. El montaje evita, asimismo, los saltos de continuidad. Sin embargo, no dejan de observarse convenciones del melodrama: primeros planos cuando los personajes lloran, empleo significativo de espejos vinculados a la identidad (José reconoce en su reflejo en un espejo roto el parecido que tiene con su padre, cuya fotografía tiene al costado; Gustavo antes de salir al encuentro con su hijo se mira en un espejo de su casa); música enfática; estructura narrativa que comprende caída (la violación), sufrimiento injusto de las víctimas, y escena de reconocimiento (en su agonía, José 
dice a su madre que ella tenía razón: su padre está muerto para él); así como secretos que acarrean desgracias y una oposición ciudad-campo en la que los personajes citadinos (Gustavo, en particular) son los villanos y los campesinos las víctimas.

El tema melodramático central de El hijo del viento es el de la filiación. Jesús Martín Barbero ha escrito que el verdadero movimiento de la trama en el melodrama es "del des-conocimiento al re-conocimiento" (1991, p. 131). El reconocimiento en los melodramas de filiación se presenta de dos maneras: es lo que busca obtener el hijo bastardo del padre; pero es también a lo que arriba el hijo pródigo al final de merecidos sufrimientos, es decir, a reconocer la bondad de sus padres que antes ha desairado. Hijos pródigos hallamos en otros filmes juliaqueños, como Triste realidad (2004) y Lágrimas de madre (2004) de Fredy Larico, que muestran a humildes madres de origen campesino padecer la incorporación de sus hijos a pandillas urbanas. En El hijo del viento, si bien el padre se niega a reconocer a su vástago, este reconoce antes de morir la abnegación de su madre, a quien antes había rechazado.

Si bien el final trágico de El hijo del viento alejaría aparentemente al relato del género, hay una afirmación de valores que no se contradice con el melodrama: la madre sufre por no haberle contado la verdad a su hijo, y esa falta conduce a la muerte del niño; la verdad, por más dolorosa que sea, debe confesarse, pues no hacerlo provoca un castigo del destino. Asimismo, el plano final del filme con el niño dirigiéndose en bicicleta al sol parecería representar su ascenso celestial. El final trágico se hallaría, de este modo, atenuado por el contenido ejemplar y el consuelo trascendental.

No obstante, no debe pasar inadvertido el contenido social de la película. Comprende una condena al abuso de quienes ostentan el poder y representan al Estado (el policía en este caso) y a la actitud de los padres que no reconocen y abandonan a sus hijos. Hay también un llamado de atención sobre el sufrimiento infantil y la violencia ejercida sobre los niños: José es azotado por su tío por no asistir a la escuela, a donde -en realidad- no se le ha dejado entrar. Resulta interesante, al respecto, la semejanza entre una escena del filme con otra de Supay, el hijo del condenado (2010) del ayacuchano Miler Eusebio: en El hijo del viento, José, lleno de ira después de haber sido impedido de ingresar a la escuela, apedrea a un sapo hasta matarlo; en la película de Miler Eusebio, el pequeño Panchito mata ferozmente con un instrumento de labranza a una gallina. Ambos son niños que se preguntan por su origen y buscan a su padre; ambos están cargados de dolor y furia.

\subsection{Amor en las alturas}

Amor en las alturas fue el primer largo de su director, Percy Pacco, residente de Juliaca, quien fue actor en dos películas de Flaviano Quispe Chaiña: 
Maylli, el abigeo (donde tuvo el rol protagónico) y Juanito, el huerfanito (en el que hizo el papel de villano).

Gran parte de Amor en las alturas fue realizado en La Rinconada, considerado el centro poblado más alto del mundo (5100 metros de altura), donde la temperatura desciende hasta $-15{ }^{\circ} \mathrm{C}$, las nevadas son frecuentes, se carece de agua potable y desagüe, y se realiza una intensa actividad minera ilegal.

Se considera que la minería ilegal mueve en el Perú alrededor de 2 mil millones de dólares al año y que ha desplazado al narcotráfico como principal actividad ilícita en el país (Acosta, 2015). En 2009, Goyzueta y Trigos consideraron que la minería en La Rinconada era "una actividad que toma gran impulso a partir de los años 80, en un contexto de precios altos de este metal, alimentada por procesos migratorios, generados por la recesión económica, la crisis de la agricultura y la violencia política", y advirtieron que el lugar se había convertido "en un escenario dramático donde familias, participan en el proceso de extracción de minerales, en una de las actividades que mayor riesgo conlleva para su desarrollo integral" ( $p$. 41). La minería ilegal que allí opera ha causado una alta contaminación de la cuenca del río Ramis, afluente del Titicaca, y de la laguna, de la que se dice que era rica en biodiversidad (Arana Zegarra, 2012). Se considera que casi el $90 \%$ de la población de La Rinconada se dedica a la minería, incluidos los niños. El sistema de trabajo al que se someten los obreros es conocido como "cachorreo", y consiste en laborar todos los días del mes sin recibir salario a condición de que en el último día se les permita llevar la mena extraída por ellos ese único día (la cual puede contener una cantidad no determinada de oro). Varias instituciones han denunciado la explotación sexual de menores en la zona, así como la pasividad de las autoridades ante este y otros delitos (Poder Ciudadano, 2012).

Aunque se han realizado reportajes y documentales sobre La Rinconada, Amor en las alturas es hasta hoy el único filme de ficción rodado en ese lugar y que alude al crecimiento de la minería ilegal. La película fue estrenada con éxito en Juliaca y recorrió, luego, otras regiones; aún hoy en día sigue siendo exhibida y rindiendo ganancia a su realizador, debido a que nunca ha sido pirateada.

Amor en las alturas cuenta una historia de destrucción de una familia por obra de un traidor. Santiago y Mario son amigos y ambos se enamoran de Carmen. Con la ayuda de Roberto, Santiago le declara su amor a Carmen y es aceptado por ella. Diez años después, Santiago y Carmen están casados y tienen un hijo. Santiago invierte su dinero en un criadero de truchas y Roberto, quien también se ha casado, posee una tienda de abarrotes. Mario labora en una mina de La Rinconada, y guarda rencor hacia Santiago y Roberto. Secretamente incendia la tienda de Roberto y roba las truchas de Santiago, obligándolos a 
buscar un trabajo en la mina, a donde acuden con sus familias. Mario, hipócritamente, les consigue trabajo en la mina; pero empieza a convertir a Santiago en alcohólico, y luego arma una intriga para acusarlo de un robo. Santiago va a la cárcel, y Mario trata de seducir a Carmen, quien lo rechaza. Mario, enfurecido, arroja a Carmen de una colina, ocasionando su muerte. En contra de lo previsto, Santiago sale de la cárcel; pero, al enterarse de la muerte de Carmen, cae más hondo en el alcoholismo, siempre azuzado por Mario, quien ha quedado impune. El hijo de Santiago le pide a su padre que no beba, pero Santiago responde que lo hace porque así se olvida de su vida miserable y ve a Carmen en sus alucinaciones. Un día, Santiago encuentra a su hijo ebrio, lo golpea, pero el pequeño le dice que se ha emborrachado para ver a su madre. Santiago, arrepentido, le pide perdón, y deja de beber ante la contrariedad de Mario, quien secuestra al hijo de Santiago y amenaza matarlo con un cartucho de dinamita encendido. Santiago lucha con él y rescata a su hijo. El cartucho explota, provocando un derrumbe que sepulta a Mario. Días después, Santiago, su hijo, Roberto y su esposa abandonan la mina y regresan a su comunidad.

La primera parte de Amor en las alturas se desarrolla en un paisaje paradisíaco, y tiene una fuerte carga humorística. La segunda parte se desarrolla en La Rinconada, y corresponde a la etapa de la caída del paraíso y el sufrimiento de los personajes. El reconocimiento que conducirá al desenlace es doble: opera con el develamiento del verdadero rostro de Mario, pero también cuando Santiago se percata de que ha sido conducido al vicio y que él está llevando a su hijo por el mismo camino. Al final, la salvación del hijo va de la mano con la muerte del malvado, y el retorno al campo supone la vuelta a la virtud y la reestructuración de la familia.

En cuanto a estilo, el escenario no puede ser más apropiado como ámbito de la caída. Las construcciones de calamina de La Rinconada, los carteles indicadores de los establecimientos (farmacia, bar, etcétera), las calles fangosas, con aguas servidas y riachuelos turbios, la lluvia y el granizo, dan al lugar un aire inclemente, casi infernal. Muchas de las escenas allí se desarrollan de noche, en claro contraste con las imágenes luminosas de la primera parte. Cuando vemos interiores, estos son estrechos y sórdidos, los hombres se tambalean adormecidos por el alcohol y las mujeres ejercen la prostitución, las habitaciones son precarias y lucen recubiertas de plásticos azules. En esta parte destaca nítidamente Óscar Gonzales Apaza en el papel del perverso Mario, especie de demonio que ha atraído a sus dominios a sus víctimas.

El filme tiene algunos problemas relacionados con la causalidad y privilegia, en ocasiones, los golpes de efecto sobre la lógica de los acontecimientos. No obstante, como hemos anotado, la débil causalidad y los efectismos no son ajenos a las 
convenciones del melodrama. Tampoco lo es la ciudadela surgida en torno a la mina como ámbito del mal, vinculada a la corrupción, el egoísmo y la codicia, en oposición al campo bucólico, familiar y productivo de donde se han visto obligadas a partir las víctimas. De otro lado, Amor en las alturas emplea ciertos recursos melodramáticos actualmente en desuso, como la verbalización que hacen los personajes (sobre todo el villano) de sus pensamientos en sombríos soliloquios.

\subsection{Marcados por el destino}

Marcados por el destino es el primer largometraje de Óscar Gonzales Apaza, quien había interpretado al villano Mario en Amor en las alturas. En Marcados por el destino también actúa y hace el papel de víctima. El filme fue pirateado a menos de un año de su estreno, lo que no le permitió al director obtener ganancias; sin embargo se trata de unos de las películas regionales de mayor calidad y más difundidas en el mercado informal.

Marcados por el destino remite a dos problemas de la región Puno: el maltrato infantil y la demencia. La primera es presentada como causa de la segunda.

Según Saavedra (2012), Puno ocupa el sexto lugar en prevalencia anual de algún trastorno psiquiátrico, tercer lugar en prevalencia anual del trastorno depresivo, quinto lugar en prevalencia anual de cualquier trastorno de ansiedad, tercer lugar en trastorno de ansiedad en adolescentes (2002-2010), tercer lugar en prevalencia de indicadores suicidas (2002-2011), octavo lugar en prevalencia anual de abuso y/o dependencia del alcohol, y primer lugar de conductas vinculadas a consumo de alcohol en adolescentes (2002-2010). “En líneas generales -dice Saavedra- las ciudades con mayores problemas de salud mental corresponden a: Ayacucho, Puno, Lima, Tacna y Puerto Maldonado" (2012, p. 49).

De otro lado, la relación que parece existir entre trauma infantil $y$ psicosis en la edad adulta ha sido objeto de estudio en investigaciones recientes de Isvoranu, Van Borkulo, Boyette, Wigman, Vinkers y Borsboom (2016); Fernández Muñiz (2016); Castro-Fernández, Perona-Carcelén, Senín-Calderón y Rodríguez Testal (2015); y Foguet Boreu, Álvarez Alonso, Santos López, Pons Baños y Arrufat Pons (2015). Estos últimos ratifican que: "Las experiencias traumáticas en la infancia se han asociado ampliamente con enfermedades mentales en la vida adulta. Estudios más recientes relacionan el hecho de haber sido víctima de abusos graves en la infancia con el desarrollo de psicosis", y señalan que algunos autores defienden la existencia de un subgrupo de esquizofrenia inducida por el trauma (Foguet Boreu et al., 2015, p. 137); al respecto citan a Read et al. en cuanto: "han concluido que el abuso infantil es un factor causal de la psicosis y la esquizofrenia y, más específicamente, 
para la aparición de determinados síntomas como las alucinaciones, particularmente las voces de comentario y las de orden" (2015, p. 138). Asimismo, Castro-Fernandez et al. indican en una de las conclusiones de su trabajo: "hemos encontrado que los sujetos con alucinaciones auditivas han padecido más acontecimientos traumáticos en la infancia" (2015, p. 102).

Marcados por el destino toca el tema directamente. El filme se inicia cuando los padres del protagonista, Valentín, son asesinados por unos delincuentes. El niño Valentín queda al cuidado de su tío Jorge, mientras sus hermanos pequeños Antonio y Lucía parten con otro tío suyo. El tío Jorge trata con crueldad a Valentín: lo golpea brutalmente, lo explota y le hace comer sobras. Ya jóvenes, Valentín, Antonio y Lucía se reencuentran en las tierras de sus padres, donde vivirán en adelante. El tío Jorge ha fallecido, pero Valentín sufre pesadillas y alucinaciones en las que su tío lo sigue maltratando. Valentín se enamora de Andrea, se casa con ella y tiene una hija, Elenita. Cuando todo parece ir bien, las alucinaciones de Valentín reaparecen. Él empieza a aislarse, a descuidar su apariencia, y su carácter sufre cambios, volviéndose violento con su hermana Lucía. Una tarde, en medio de sus alucinaciones, Valentín confunde a Lucía con su tío Jorge, y la estrangula. Sus alucinaciones se intensifican y pierde la cordura, huye de la casa pero es rescatado por sus familiares. Andrea trata de convencerlo de ir a la ciudad a buscar la ayuda de un especialista. Valentín se niega, trata de huir de nuevo, y Andrea intenta detenerlo. Forcejean. Andrea cae y sufre un golpe que la deja inconsciente. Valentín, desesperado, la lleva al centro de salud de Capachica. Mientras Andrea se recupera, Valentín accede a tratarse con un psiquiatra a quien le cuenta que mató a su hermana Lucía. El médico le anuncia que Andrea ya está consciente y se encuentra embarazada. Andrea perdona a Valentín.

Desde el título, que alude a la marca (o herida) y al destino, la película se define como un melodrama. La estructura narrativa corresponde plenamente al género. La muerte violenta de los padres determinará la pérdida del paraíso familiar y dejará una marca o herida abierta en el protagonista. Hay, luego, un sufrimiento injusto (el maltrato del que es víctima Valentín por parte de su tío), y cuando parece que el protagonista puede reencontrar la felicidad al reunirse con sus hermanos y casarse con Andrea (es decir, cuando el paraíso familiar está a punto de recuperarse), el sufrimiento renace al manifestarse la esquizofrenia que lo mortifica. Sin embargo, luego de haber tocado fondo (Valentín, presa de su enfermedad, ha matado a su hermana Lucía y está a punto de matar a Andrea), y previa anagnórisis (el reconocimiento de Valentín de su mal y de su necesidad de ayuda), emerge la resolución consoladora del conflicto. La estructura, además, contiene varios flashbacks, que remiten a momentos felices y refuerzan la tristeza del presente. 
El filme incluye escenas propias del género, como aquella en la que Valentín observa con aprensión (como si temiera convertirse en alguien así) a un demente que solo emite sonidos guturales y risa. La imagen del otro es, de este modo, como un espejo para el protagonista. Hay, asimismo, un buen empleo melodramático del paisaje: en la declaratoria de amor entre Valentín y Andrea, el lago aporta su infinitud y pureza; en las escenas de cortejo, el campo otorga al juego amoroso un sentido bucólico.

Se aprecia, además, un énfasis estilístico en la música, que apunta a generar una reacción emotiva de los espectadores: el personaje de Lucía, desde niña, tiene un tema musical humorístico que la caracteriza (leitmotiv) como un ser travieso e inocente, lo que hará más lamentable aún su trágica muerte. Aunque los movimientos de cámara son, en su mayoría, suaves, variados y armoniosos, en algunas escenas resultan sumamente elocuentes. Una toma muy lograda es aquella en la que Valentín, enloquecido, huye del hogar por un camino sinuoso hacia las montañas, perseguido por sus fantasmas, mientras Andrea se aleja en sentido contrario, cargando a su hija y llorando por la locura de su marido, a la vez que la cámara hace un enfático movimiento de grúa.

\section{Conclusiones}

La asimilación y empleo de las convenciones del género melodramático en los filmes analizados facilitan su comunicación con un público masivo y popular.

Los melodramas juliaqueños representan problemas sociales actuales de la región Puno que ninguna película limeña de ficción ha abordado hasta hoy.

Los melodramas juliaqueños presentan figuras negativas del padre, que podrían interpretarse como metáforas del Estado. El padre (o quien debe asumir ese rol) se halla ausente (El hijo del viento), es débil (Amor en las alturas) o es abusivo (Marcados por el destino).

Los melodramas juliaqueños expresan cómo se vive la modernidad en la región Puno desde los sectores populares. El video digital, empleado como soporte de estas películas, es también un producto de la modernidad vivida por la población hacia la cual se dirigen los filmes.

\section{Referencias}

Acosta, Ch. (26 de mayo de 2015). Perú, país minero (legal). Recuperado de https://revistapoder.lamula. pe/2015/05/26/peru-pais-minero-ilegal/poder/

Arana Zegarra, M. (18 de diciembre de 2012). El derecho al agua en comunidades afectadas por 
actividades mineras. Recuperado de http://www.conflictosmineros.net/ noticias/19-peru/11634-el-derechoal-agua-en-comunidades-afectadaspor-actividades-mineras

Bordas, C. (2009). "Mientras Puno danza, Juliaca avanza...": El proceso de urbanización en las orillas del lago Titicaca (departamento de Puno, Perú). En Cáceres-Olazo Monroy, J. M. (Ed.). Cultura, historia y sociedad en la meseta del Q'ollao. Lima: Universidad Nacional Federico Villarreal, Facultad de Humanidades, departamento Académico de Historia, Antropología y Arqueología: Colegio Profesional de Antropólogos, Consejo Departamental Descentralizado Lima.

Bordwell, D, (1996). La narración en el cine de ficción. Barcelona: Paidós.

Brooks, P. (1995). The Melodramatic Imagination: Balzac, Henry James, Melodrama, and The Mode of Excess. New Haven: Yale University Press.

Bourricaud, F. (2012). Cambios en Puno. Estudios de sociología andina. Lima: Instituto de Estudios Peruanos.

Castro-Fernández, M. P., PeronaCarcelén, S., Senín Calderón, C. y Rodríguez-Testal, J. F. (2015). Relación entre trauma, disociación y síntomas psicóticos positivos. [Relationship of Trauma, Dissociation, and Positive Psychotic Symptoms]. Acción Psicológica, 12(2), 95-108. doi: http://dx.doi. org/10.5944/ap.12.2.15824
Estébanez Calderón, D. (2001). Diccionario de términos literarios. Madrid: Alianza Editorial.

Fernández Muñiz, C. (2016). Implicación del trauma infantil en el desarrollo de primeros episodios de psicosis [The Role of Childhood Trauma in First Episode of Psychosis Development] (Grado en Medicina. Trabajo de fin de grado). Facultad de Medicina, Universidad de Cantabria.

Foguet Boreu, Q., Álvarez Alonso, M. J., Santos López, J. M., Pons Baños. J. y Arrufat Pons, F. X. (2009). Trauma infantil y esquizofrenia. Psiquiatría Biológica, 16(3), 137-139.

Goyzueta, G. y Trigos, C. (2009). Riesgos de salud pública en el centro poblado minero artesanal $\mathrm{La}$ Rinconada (5200 msnm) en Puno, Perú. Revista Peruana de Medicina Experimental y Salud Publica, 26(1), 41-44.

Herlinghaus, H. (Ed) (2002). Narraciones anacrónicas de la modernidad. Melodrama e intermedialidad en América Latina. Santiago de Chile: Cuarto propio.

INEI \& Unicef (2011). Estado de la niñez en el Perú. Lima: Tarea.

Isvoranu, A-M; Van Borkulo, CD; Boyette. L-L, Wigman, J. T. W.; Vinkers, Ch. H.; y Borsboom, D. (mayo 2016). A Network Approach to Psychosis: Pathways Between Childhood Trauma and Psychotic Symptoms. Schizophrenia Bulletin Advance Access. doi: 10.1093/schbul/sbw055 
Martín Barbero, J. (1991). De los medios a las mediaciones. Barcelona: Gustavo Gili.

Pérez Rubio, P. (2004). El cine melodramático. Barcelona: Paidós.

Poder Ciudadano (20 de febrero de 2013). Más de mil menores de edad son víctimas de explotación sexual en La Rinconada. Recuperado de https://poderciudadano.lamula. pe/2013/02/20/mas-de-mil-menores-de-edad-son-victimas-de-ex- plotacion-sexual-en-la-rinconada/ poderciudadano/

Saavedra, J. E. (2012). Panorama de la salud mental en el Perú. Perú: Ministerio de Salud, Instituto Nacional de Salud Mental. Recuperado de http:// www.fdm.org.pe/documentos/ SIMP_MENTAL_Panorama_Salud_ Mental_Peru_DrSaavedra_110614.pdf Thomasseau, J-M. (1984). El melodrama. México: Fondo de Cultura Económica. 